\title{
The Pituitary Gland Measurements in Sudanese Females using Magnetic Resonance Imaging
}

\author{
Shayma Hamed ${ }^{1}$; Ayad CE ${ }^{1}$; Rana A Eisa ${ }^{2}$; Awadia Gareeballah ${ }^{3,4}$; \\ Alaa Ibrahim ${ }^{5,6}$; Moawia Gameraddin ${ }^{3}$; Samih Kajoak \\ ${ }^{1}$ Sudan University of Science and Technology, College of Medical Radiology Sciences, Khartoum, Sudan \\ ${ }^{2}$ College of Applied Studies and Community Services, Health Sciences Department, \\ King Saud University, Riyadh, Saudi Arabia \\ ${ }^{3}$ Department of Diagnostic Radiologic Technology, Faculty of Applied Medical Sciences, \\ Taibah University, Al-Madinah Al-Munawara, Saudi Arabia \\ ${ }^{4}$ Faculty of Radiological Sciences and Medical Imaging, Alzaeim Alazhari University University, \\ Khartoum, Sudan \\ ${ }^{5}$ Department of Radiological Sciences, Al-Ghad International College, Tabouk, Saudi Arabia \\ ${ }^{6}$ University of Medical Sciences and Technology, Khartoum, Sudan \\ ${ }^{7}$ Department of Diagnostic Radiologic Sciences, College of Applied Medical Sciences, Taif University, \\ Taif, Saudi Arabia
}

\begin{abstract}
Background: Assessment of the pituitary gland (PG) measurements is essential for the diagnosis of many pathological conditions. For Sudanese adult females, however, there have been no studies and no reference values for PG measurements. Therefore, the aim of this study was to determine the regular dimensions of the PG, using MRI, and to correlate these measurements with age, the shape of sella turcica, puberty age, and parity in Sudanese females.

Methods and Results: This cross-sectional study was done to assess the PG measurement in Sudanese adult females ( $\mathrm{n}=63$ ) aged between 20 years and 60 years who underwent a brain MRI examination between 2015 and 2019. The study was conducted at Yastabshiroon Umodorman Medical Center (Khartoum, Sudan). The MRI brain examination found that the mean length, depth, width, and volume of the PG were $10.57 \pm 1.27 \mathrm{~mm}, 5.56 \pm 1.42 \mathrm{~mm}, 12.18 \pm 1.67 \mathrm{~mm}$, and $356.38 \pm 100.22 \mathrm{~mm}^{3}$, respectively. Concerning the shape of the sella turcica, the study revealed that the convex and concave shape were more frequent than others (39.7\% and $34.9 \%$, respectively). The depth, width, length, and volume of the gland had changed significantly with pituitary shapes. The PG depth was significantly higher in nulliparous females than multiparous ones.

Conclusion: The PG measurement in adult Sudanese females decreased in the sagittal depth and volume gradually till the age of 50 years then returned to increasing after age 50. Younger females in the age group of 20-30 years had a larger depth and volume of the gland than other age groups. (International Journal of Biomedicine. 2020;10(4):397-401.)
\end{abstract}

Key Words: female $\bullet$ pituitary gland $\bullet$ magnetic resonance imaging $\bullet$ age $\bullet$ parity $\bullet$ puberty age

\section{Introduction}

The pituitary gland (PG) lies in the pituitary fossa beneath the body of the sphenoid bone. The size of the sphenoid sinus and sella turcica, including the depth and shape of the PG, usually have significant variations in different individuals. ${ }^{(1)} \mathrm{MRI}$ is an accurate diagnostic imaging method for assessing the PG size and shape. Changes are noted in the pituitary signal's size, shape, and intensity, reflecting changes in the gland's hormonal function. There are several pituitary disorders, such as physiological hypertrophy, inflammatory changes, and empty sella turcica. The shape and size of the normal PG often change during one's lifespan and are affected by age and gender. ${ }^{(2,3)}$ 
Previous studies have found that there is a wide variation of pituitary size associated with age and gender. The variation in PG volume depends on hormonal status. Thus, due to hormonal activity younger adults show a larger pituitary during puberty and, in females, during pregnancy. ${ }^{(4-8)}$

MRI of PG in females is essential to assess females' pituitary size and volume. It has been reported that PG is affected by age, parity, puberty age, and hormone-related factors.

\section{Materials and Methods}

This cross-sectional study was done to assess the PG measurement in Sudanese adult females $(n=63)$ aged between 20 years and 60 years who underwent a brain MRI examination between 2015 and 2019. The study was conducted at Yastabshiroon Umodorman Medical Center (Khartoum, Sudan). Written informed consent was obtained from each patient.

The data were collected from 63 Sudanese adult females between 20 and 60 years of age, classified into 4 age groups (mean age of $35.52 \pm 11.11$ years) in puberty and menopausal categories, and puberty age ranged between 10 years and 19 years. The sample was selected randomly. Inclusion criteria were Sudanese women of indicated age with no medical or pathological condition that may affect PG shape and measurement. The exclusion criteria were pituitary abnormalities or previous intracranial surgery. Any woman with a disturbance of pituitary hormones or schizophrenia was excluded from the study.

\section{MRI technique}

MRI of the brain was performed using a General Electric Healthcare (GE SIGNA EXCITE) machine with a $0.2 \mathrm{~T}$ permanent magnet (open magnet). A standard head coil was used for acquiring the images. The sagittal and axial views were displayed using the midline plane of T1weighted image spine-echo, matrix size was $512 \times 512$, FOV was $24 \times 18$ (repetition time/echo time of $450 / 10.5 \mathrm{~ms}$, $378 / 8.6 \mathrm{~ms}$ ), and slice thickness of $6.3 \mathrm{~mm}$. Foam pads and straps were used for immobilization. The patient lay supine on the examination table with the head placed carefully in the head coil. The head was adjusted with the interpupillary line parallel to the table. The longitudinal alignment light lies were adjusted in the midline and horizontal alignment to pass through the nasion. Three axial sequences, T1-weighted image, T2-weighted image, and fluid-attenuated inversion recovery (FLAIR) were utilized. T1 sagittal image and T2 coronal image with additional sequences were used to assess the pituitary measurements. PG was measured in thin, sagittal, axial sections. The measurements were done in the Dicom imager program. The sagittal depth of PG was measured as the pituitary's vertical distance, defined by a line connecting two maximum top-bottom points in the T1-weighted sagittal section (Fig. 1A). The maximum anteroposterior diameter called (sagittal length) was measured as the longitudinal distance, defined by the line connecting two corners of the PG longitudinally (Fig. 1B) T1-weighted sagittal section. The axial width was measured by the maximum two-point distances from the right to left borders of the PG in the axial section (Fig. 1C).
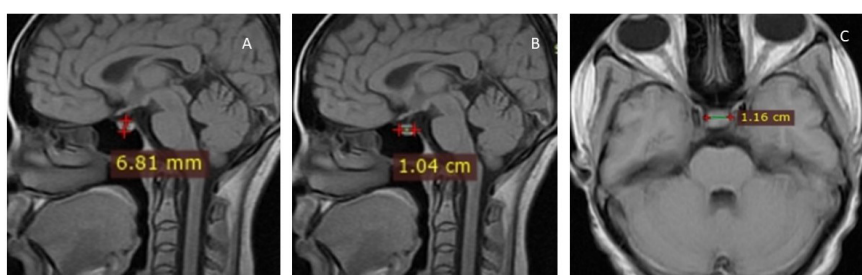

Fig. 1. MRI images show pituitary measurements taken with spin echo sequence, TR 600, TE 14. A\& B-T1-weighted sagittal images; $C$ - T1-weighted axial image taken with TR 350 and TE 7.8.

The PG volume was calculated using an ellipsoid object's formula:

Di Chiro and Nesion formula ( Vol $=$ length $\times$ depth $\times$ width $\times 0.5$ ).

The shape of the PG in the sagittal view according to the upper surface was determined as: "Convex" (round shape) (Fig. 2A); "Concave" (Fig. 2B); "Flat" (Fig. 2C); Partial empty (PE) - the gland high of 3-4 mm (Fig. 2D); Empty sella turcica - the gland height $\leq 2 \mathrm{~mm}$ (Fig. 2E).
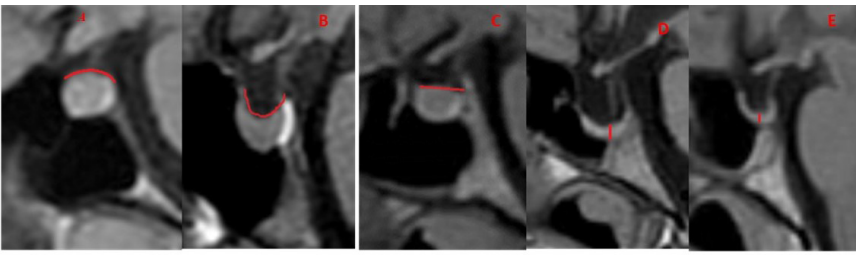

Fig.2. Different shapes of the sella turcica. A: Convex shape, B: Concave shape, C: Flat shape, D: Partial empty, E: Empty shape

Statistical analysis was performed using IBM SPSS Statistics 23. Continuous variables were presented as mean \pm standard deviation (SD). Multiple comparisons were performed with one-way ANOVA The linear regression model and coefficient of determination $\left(\mathrm{R}^{2}\right)$ were calculated. Pearson's correlation coefficient (r) was used to determine the strength of the relationship between the two continuous variables. A probability value of $P<0.05$ was considered statistically significant.

\section{Results}

The MRI brain examination found that the mean length, depth, width, and volume of the PG were $10.57 \pm 1.27 \mathrm{~mm}$, $5.56 \pm 1.42 \mathrm{~mm}, 12.18 \pm 1.67 \mathrm{~mm}$, and $356.38 \pm 100.22 \mathrm{~mm}^{3}$, respectively (Table 1 ).

Concerning the shape of the sella turcica, the study revealed that the convex and concave shape were more frequent than others (39.7\% and 34.9\%, respectively) (Table (2).

The depth, width, length, and volume of the gland had changed significantly with pituitary shapes. It was observed that the flat shape yields the highest volume, followed by the convex, then concave, while the partially empty and empty 
sella turcica yield a lower volume. The sagittal depth was higher in the convex shape $(6.75 \pm 0.75 \mathrm{~mm})$, and axial width was higher in the partially empty sella turcica $(13.02 \pm 1.59$ $\mathrm{mm})$. The sagittal length and volume were higher in flatshaped sella turcica $\left(11.76 \pm 0.7 \mathrm{~mm}\right.$ and $419.89 \pm 31.72 \mathrm{~mm}^{3}$, respectively) (Table 3).

Table1.

Descriptive statistics for PG measurement

\begin{tabular}{|l|c|c|c|}
\hline \multicolumn{1}{|c|}{ Variables } & Minimum & Maximum & Mean \pm SD \\
\hline Age, years & 20 & 60 & $35.52 \pm 11.11$ \\
\hline Puberty age, years & 10 & 19 & $14.16 \pm 1.54$ \\
\hline Sagittal length, $\mathrm{mm}$ & 6.1 & 13.5 & $10.57 \pm 1.27$ \\
\hline Sagittal depth, $\mathrm{mm}$ & 2.0 & 8.3 & $5.56 \pm 1.42$ \\
\hline Axial width, mm & 8.4 & 15.5 & $12.18 \pm 1.67$ \\
\hline Volume, $\mathrm{mm}^{3}$ & 98.0 & 563.1 & $356.38 \pm 100.22$ \\
\hline
\end{tabular}

Table 2.

The frequency of shapes of the sella turcica

\begin{tabular}{|l|c|c|}
\hline \multicolumn{1}{|c|}{ Shape } & Frequency & Percent \\
\hline Convex & 25 & 39.7 \\
\hline Concave & 22 & 34.9 \\
\hline Flat & 9 & 14.3 \\
\hline Partial empty & 5 & 7.9 \\
\hline Empty & 2 & 3.2 \\
\hline Total & 63 & 100.0 \\
\hline
\end{tabular}

Table 3.

Association of PG measurements with pituitary shape, age groups, and puberty age

\begin{tabular}{|c|c|c|c|c|}
\hline Variables & $\begin{array}{c}\text { Sagittal } \\
\text { length, mm }\end{array}$ & $\begin{array}{c}\text { Sagittal } \\
\text { depth, mm }\end{array}$ & $\begin{array}{c}\text { Axial } \\
\text { width, mm }\end{array}$ & $\underset{\mathrm{mm}^{3}}{\text { Volume, }}$ \\
\hline \multicolumn{5}{|c|}{ Pituitary shapes } \\
\hline Convex & $10.25 \pm 1.22$ & $6.75 \pm 0.75$ & $11.54 \pm 1.72$ & $398.63 \pm 84.31$ \\
\hline Concave & $10.46 \pm 1.26$ & $5.08 \pm 0.63$ & $12.69 \pm 1.54$ & $337.55 \pm 71.32$ \\
\hline Flat & $11.76 \pm 0.71$ & $5.68 \pm 0.67$ & $12.69 \pm 1.30$ & $419.89 \pm 31.72$ \\
\hline Partial empty & $10.83 \pm 1.60$ & $3.02 \pm 0.43$ & $13.02 \pm 1.59$ & $216.70 \pm 67.96$ \\
\hline Empty & $9.85 \pm 0.21$ & $1.96 \pm 0.00$ & $10.25 \pm 0.35$ & $98.90 \pm 1.28$ \\
\hline$P$-value & 0.030 & 0.000 & 0.030 & 0.000 \\
\hline \multicolumn{5}{|c|}{ Age groups, years } \\
\hline $20-30$ & $10.23 \pm 1.82$ & $6.14 \pm 1.25$ & $11.79 \pm 1.49$ & $371.387 \pm 101.25$ \\
\hline $31-40$ & $10.90 \pm 1.47$ & $5.17 \pm 1.10$ & $12.52 \pm 1.87$ & $350.54 \pm 97.96$ \\
\hline $41-50$ & $10.29 \pm 0.98$ & $5.04 \pm 1.77$ & $12.47 \pm 1.59$ & $326.47 \pm 118.52$ \\
\hline $51-60$ & $11.50 \pm 0.67$ & $5.32 \pm 1.45$ & $12.33 \pm 2.01$ & $367.92 \pm 71.40$ \\
\hline$P$-value & $<0.05$ & $>0.05$ & $>0.05$ & $>0.05$ \\
\hline \multicolumn{5}{|c|}{ Puberty age, years } \\
\hline $10-13$ & $10.91 \pm 0.87$ & $5.45 \pm 1.41$ & $12.25 \pm 1.72$ & $366.83 \pm 105.56$ \\
\hline $14-16$ & $10.24 \pm 10.72$ & $5.80 \pm 1.45$ & $12.02 \pm 1.69$ & $351.98 \pm 100.51$ \\
\hline $17-19$ & $10.72 \pm 1.32$ & $4.79 \pm 1.06$ & $12.81 \pm 1.46$ & $324.29 \pm 71.07$ \\
\hline$P$-value & $>0.05$ & $>0.05$ & $>0.05$ & $>0.05$ \\
\hline
\end{tabular}

There was a significant difference in sagittal length in different age groups $(P<0.05)$; it increased gradually till the age of 40 , then decreased in length in the age group of 41 50 years. It increased significantly in the 51-60 group. There was no significant difference in sagittal depth, axial width, and volume measurement in different age groups. The mean depth in the age group of $20-30$ years was $6.14 \pm 1.25 \mathrm{~mm}$, while in the age group of 41-50 it was $5.04 \pm 1.77 \mathrm{~mm}$, and then it returned to increase to $5.32 \pm 1.45 \mathrm{~mm}$ in the age group of 51-60 years. The volume was $371.387 \pm 101.25 \mathrm{~mm}^{3}$ in the age group of 20-30 years, then it decreased to $326.47 \pm 118.52 \mathrm{~mm}^{3}$ in the age group of 41-50 years and returned to increase again after 50 years to $367.92 \pm 71.40 \mathrm{~mm}^{3}$ (Table 3 ).

The PG measurement has no significant association with the puberty age. Generally, the volume and depth were higher at the early puberty age than in the late one. The volume was $366.83 \pm 105.56 \mathrm{~mm}^{3}$ and $324.29 \pm 71.07 \mathrm{~mm}^{3}$ in puberty age of 10-13 years and 17-19 years, respectively. The depth was $5.45 \pm 1.41 \mathrm{~mm}$ and $4.79 \pm 1.06 \mathrm{~mm}$ in puberty age of $10-13$ years and $17-19$ years, respectively (Table 3 ).

The PG sagittal depth was significantly different among parity groups $(P<0.05)$. The depth was significantly higher in nulliparous females than multiparous ones (Table 4). The other pituitary measurements (sagittal length, axial width, and volume) didn't vary significantly with parity; in general the volume also was greater in nulliparous than in multiparous women (Table 4).

Table 4.

PG measurement and parity groups

\begin{tabular}{|l|c|c|c|c|}
\hline \multicolumn{1}{|c|}{ Parity } & $\begin{array}{c}\text { Sagittal } \\
\text { length, mm }\end{array}$ & $\begin{array}{c}\text { Sagittal } \\
\text { depth, } \mathrm{mm}\end{array}$ & $\begin{array}{c}\text { Axial } \\
\text { width, } \mathrm{mm}\end{array}$ & $\begin{array}{c}\text { Volume, } \\
\mathrm{mm}^{3}\end{array}$ \\
\hline Nulliparous & $10.47 \pm 1.43$ & $6.18 \pm 1.20$ & $11.93 \pm 1.66$ & $379.32 \pm 80.66$ \\
\hline $1-3$ & $10.18 \pm 1.36$ & $4.61 \pm 1.59$ & $12.18 \pm 1.68$ & $294.81 \pm 132.60$ \\
\hline $4-6$ & $10.93 \pm 1.12$ & $5.36 \pm 1.38$ & $12.45 \pm 1.78$ & $362.28 \pm 101.91$ \\
\hline $7-10$ & $10.55 \pm 1.03$ & $5.20 \pm 1.35$ & $12.35 \pm 1.68$ & $341.53 \pm 101.22$ \\
\hline P-value & $>0.05$ & $<0.05$ & \multicolumn{3}{|c|}{$>0.05$} \\
\hline
\end{tabular}

The study found no significant correlation of the PG measurements with age, puberty age, and parity (Table 5).

\section{Table 5.}

Correlation of the PG measurements with age, puberty age, and parity

\begin{tabular}{|l|l|c|c|c|}
\hline \multicolumn{2}{|c|}{ Variables } & Age & Puberty age & Parity \\
\hline \multirow{2}{*}{$\begin{array}{l}\text { Sagittal length, } \\
\text { mm }\end{array}$} & Pearson Correlation & 0.221 & -0.172 & 0.045 \\
\cline { 2 - 5 } & Sig. (2-tailed) & 0.082 & 0.178 & 0.728 \\
\hline $\begin{array}{l}\text { Sagittal depth. } \\
\text { mm }\end{array}$ & Pearson Correlation & -0.235 & -0.006 & -0.235 \\
\cline { 2 - 5 } & Sig. (2-tailed) & 0.064 & 0.963 & 0.064 \\
\hline \multirow{2}{*}{$\begin{array}{l}\text { Axial width, } \\
\text { mm }\end{array}$} & Pearson Correlation & 0.099 & -0.041 & 0.145 \\
\cline { 2 - 5 } & Sig. (2-tailed) & 0.440 & 0.752 & 0.257 \\
\hline $\begin{array}{l}\text { Volume, } \\
\mathrm{mm}^{3}\end{array}$ & Pearson Correlation & -0.089 & -0.139 & -0.097 \\
\cline { 2 - 5 } & Sig. (2-tailed) & 0.490 & 0.277 & 0.451 \\
\hline
\end{tabular}


Table 6 summarizes the association of the sella turcica shape with age groups. The convex shape was prominent in the age group of 20-30 years, while the concave shape was frequent in the age group of 31-40 years. This finding indicates that the sella turcica shape was significantly different among age groups $(P=0.028)$.

Table 6.

Cross tabulation between age groups and shape of the sella turcica

\begin{tabular}{|c|c|c|c|c|c|}
\hline \multirow{2}{*}{ Shape } & \multicolumn{4}{|c|}{ Age group } & \multirow{2}{*}{ Total } \\
\hline & $20-30$ & $31-40$ & $41-50$ & $51-60$ & \\
\hline Convex & 16 & 4 & 3 & 2 & 25 \\
\hline Concave & 7 & 9 & 5 & 1 & 22 \\
\hline Flat & 2 & 1 & 2 & 4 & 9 \\
\hline Partial empty & 0 & 2 & 2 & 1 & 5 \\
\hline Empty & 1 & 0 & 1 & 0 & 2 \\
\hline Total & 26 & 16 & 13 & 8 & 63 \\
\hline \multicolumn{6}{|c|}{$P=0.028^{*}$} \\
\hline
\end{tabular}

There was an inverse relationship between females' age and pituitary depth and volume (Fig.3-5). From this linear correlation, the study predicts the depth and volume of the gland by identifying the female's age, as follows:

PG depth $=-0.0304 \times$ age $+6.6496\left(\mathrm{R}^{2}=0.0563\right)$

$\mathrm{PG}$ volume $=-0.08 \times$ age $+384.81\left(\mathrm{R}^{2}=0.0079\right)$

The following equations indicate an inverse relationship between the gland's volume and puberty age (Fig.5):

PG depth $=-9.0162 \times$ puberty age $+484.05\left(\mathrm{R}^{2}=0.0194\right)$

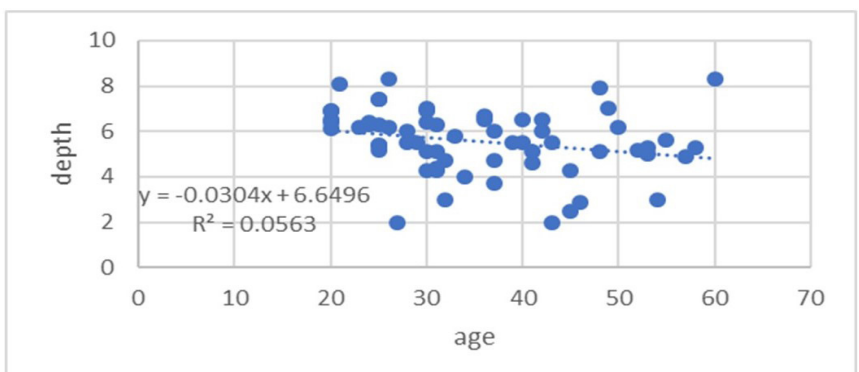

Fig.3. Linear relationship between $P G$ depth and age.

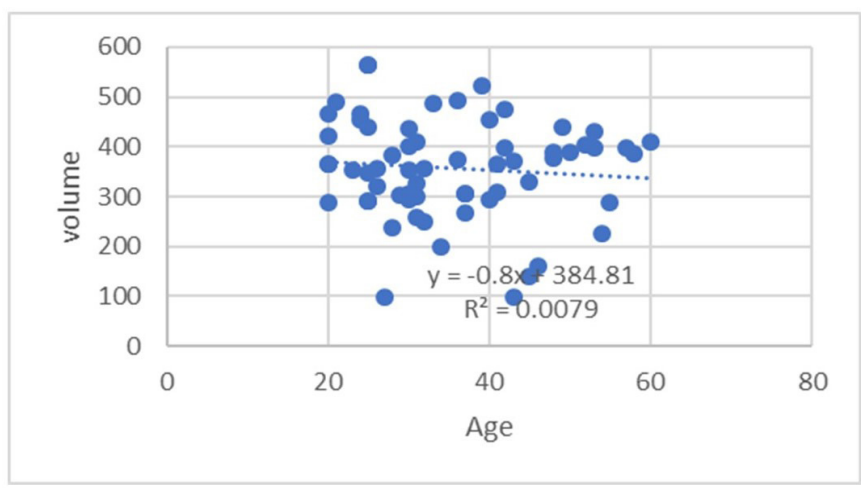

Fig. 4. Linear relationship between $P G$ volume and age

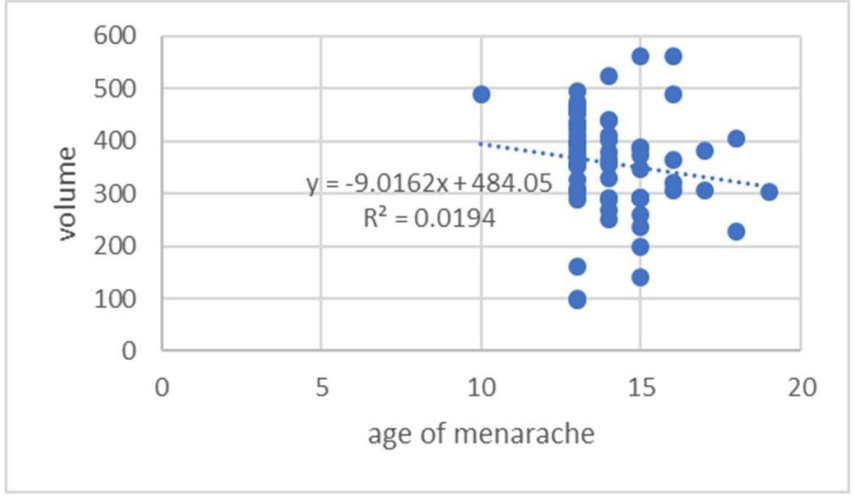

Fig. 5. Linear relationship between volume and puberty age

\section{Discussion}

The study evaluated the shape, mean volume, depth, width, and length of the normal PG in females, related to age, puberty age, and parity using MRI. In this study, females' pituitary height was higher than in a study performed by A. Tsunoda, ${ }^{(4)}$ who reported a mean value of $5.35 \pm 1.2 \mathrm{~mm}$. The PG height was less in this study than in a study performed by Singh et al. ${ }^{(10)}(5.80 \pm 1.32 \mathrm{~mm})$. Ibinaiye et al ${ }^{(9)}$ reported that the mean PG volume for females in North Nigeria was $328.1 \pm 129.2 \mathrm{~mm}^{3}$. Our findings for the PG agree with data of Singh et al. ${ }^{(10)}\left(354.98 \pm 130.60 \mathrm{~mm}^{3}\right)$.

The current study found that the convex and concave shapes were more common than other shapes. In contrast, Yadav et al. ${ }^{(2)}$ found that the most common shape was flat. Singh et al. ${ }^{(10)}$ found that convex in females was mostly seen in the age group of 10-29 years. In our study, convex shapes were more frequent in the age group of 20-30 years.

The current study clarified that the PG yielded the most considerable depth and volume in females of 20-30 years. The depth and volume then declined till the age of 50 years, and then returned to increasing. Yadav et al $^{(2)}$ found that in the age group of 21-30 years, the mean PG volume was $440 \pm 180$ $\mathrm{mm}^{3}$, in the $31-40$ group - $440 \pm 111 \mathrm{~mm}^{3}$, in $41-50$ group $420 \pm 116 \mathrm{~mm}^{3}$, and in females over age $50-420 \pm 174 \mathrm{~mm}^{3}$. Our findings agree with data of Ibinaiye et al., ${ }^{(9)}$ who reported that the PG depth and volume increased in pubertal subjects, then decreased steadily with increasing age, with a second peak noted only for pituitary height in the sixth decade.

Our study found that PG depth yielded the highest value in the age group of 20-30 years, then declined till the age of 50 years. After age 50, the depth returned to increasing. This finding is consistent with Yadav et al. ${ }^{(2)}$ and Tsunoda et al. ${ }^{(4)}$, who reported the same results. Tsunoda et al. ${ }^{(4)}$ found that the PG height reached a peak value in the age group of 2029 years, then returned to increasing again in the age group of 50-59. Doraiswamy, ${ }^{(8)}$ on the other hand, found that the depth decreased until the age of 59 and increased from 60-69 years. In contrast, many studies found that the PG reached the highest value of depth in the third decade of life, ${ }^{(2,4,8)}$ while other studies found that the PG yields the largest peak at the age of 10-19 years. ${ }^{(3,1)}$ Previous studies attributed the changes in pituitary measurements to changes in hormone levels, 
which might be the cause of such changes in the pituitary morphology. The elevation in PG height during puberty can be related to the increased production of a luteinizing hormone during this time of growth. Also, the greater PG height was observed in young patients. . $^{(2,8,11,12)}$

Previous studies have reported that PG depth increases in elderly subjects, which is considered compensatory hypertrophy after a significant reduction in a gonadal steroid feedback effect. The pituitary size is greater in adolescence due to physiology hypertrophy in females, which occurs as a result of changes in hormones associated with menstruation; the reduced PG size between the second and sixth decades of life may reflect neuroendocrinology of aging and physiologic pituitary atrophy. (2,6, $8,11,12)^{2}$

The study found that there was a significant difference in the sagittal length of the PG measurement in different age groups. It increased gradually until the age of 40 years, then decreased at age 41-50 years and increased significantly at age 51-60 years. A significant difference in sagittal depth measurement was found in different parity groups and was more significant in nulliparous than multiparous women. In our study, the nulliparous females had a larger PG than other groups of parity. This finding is consistent with Daghighi et al., ${ }^{(13)}$ who stated that the gland's volume is greatest in nulliparous women.

Concerning the PG measurement in females with PG of different shapes, a significant difference was found between measurement in glands of different shapes as the flat shape yielded the highest volume followed by convex then concave, while the partially empty and empty sella turcica yield a lower volume.

We found no significant correlation between gland measurements, age, puberty age and parity. In general, as female age, puberty age, and parity increased, sagittal depth and volume of the PG decreased. There was an insignificant inverse correlation between the depth, the volume of PG with age, puberty, and parity. In contrast, Daghighi et al. ${ }^{(13)}$ found that gravidity and parity had a significant negative impact on PG volume $(P<0.01)$. The insignificant relationship in our study may be due to the small sample size.

\section{Conclusion}

Thus, the mean measurements (length, depth, width, and size) of PG in females changed significantly with the pituitary shapes. The PG measurement in adult Sudanese females decreased in the sagittal depth and volume gradually till the age of 50 years then returned to increasing after age 50 . Younger females in the age group of 20-30 years had a larger depth and volume of the gland than other age groups. The pituitary volume increased in females with early onset of puberty age, and in nulliparous females. The convex-shaped gland was more prevalent in younger individuals of 20-30 years. Further studies with a larger sample size with a hormonal profile should be performed for more accurate results.

\section{Competing Interests}

The authors declare that they have no competing interests.

\section{Acknowledgments}

We would like to extend our sincere gratitude to Yastabshiroon Umodorman Medical Center (Khartoum, Sudan) for ethical approval to collect data for this study and help us in data collection.

\section{References}

1. John S, Avinash Kumar K, Nicola S, Sudarshan T, Prasad G. MRI Measurement of Normal Pituitary Size Using Volumetric Imaging in Scottish Patients. Curr Trends Clin Med Imaging. 2017; 1(3): 555563. doi: 10.19080/CTCMI.2017.01.555563

2. Yadav P, Singhal S, Chauhan S, Harit S. MRI Evaluation of Size and Shape of Normal Pituitary Gland: Age and Sex Related Changes. Journal of Clinical and Diagnostic Research. 2017. 11(12): TC01-TC04. doi:10.7860/JCDR/2017/31034/10933

3. Suzuki M, Takashima T, Kadoya M, Konishi H, Kameyama $\mathrm{T}$, Yoshikawa J, et al. Height of normal pituitary gland on MR imaging: age and sex differentiation. J Comput Assist Tomogr. 1990 Jan-Feb;14(1):36-9. doi: 10.1097/00004728199001000-00006.

4. Tsunoda A, Okuda O, Sato K. MR height of the pituitary gland as a function of age and sex: especially physiological hypertrophy in adolescence and in climacterium. AJNR Am J Neuroradiol. 1997 Mar;18(3):551-4.

5. Ikram MF, Sajjad Z, Shokh I, Omair A. Pituitary height on magnetic resonance imaging observation of age and sex related changes. J Pak Med Assoc. 2008 May;58(5):261-5.

6. Janssen YJ, Doornbos J, Roelfsema F. Changes in muscle volume, strength, and bioenergetics during recombinant human growth hormone $(\mathrm{GH})$ therapy in adults with $\mathrm{GH}$ deficiency. J Clin Endocrinol Metab. 1999 Jan;84(1):279-84. doi: 10.1210/jcem.84.1.5411.

7. Ju KS, Bae HG, Park HK, Chang JC, Choi SK, Sim KB. Morphometric study of the korean adult pituitary glands and the diaphragma sellae. J Korean Neurosurg Soc. 2010 Jan;47(1):427. doi: 10.3340/jkns.2010.47.1.42. Epub 2010 Jan 31.

8. Doraiswamy PM, Potts JM, Axelson DA, Husain MM, Lurie $\mathrm{SN}, \mathrm{Na} \mathrm{C}$, et al. MR assessment of pituitary gland morphology in healthy volunteers: age- and gender-related differences. AJNR Am J Neuroradiol. 1992 Sep-Oct;13(5):1295-9.

9. Ibinaiye PO, Olarinoye-Akorede S, Kajogbola O, Bakari AG. Magnetic Resonance Imaging Determination of Normal Pituitary Gland Dimensions in Zaria, Northwest Nigerian Population. J Clin Imaging Sci. 2015 May 29;5:29. doi: 10.4103/2156-7514.157853.

10. Singh AKC, Kandasamy D, Garg A, Jyotsna VP, Khadgawat R. Study of Pituitary Morphometry Using MRI in Indian Subjects. Indian J Endocrinol Metab. 2018 SepOct;22(5):605-609. doi: 10.4103/ijem.IJEM_199_18

11. Elster AD, Chen MY, Williams DW 3rd, Key LL. Pituitary gland: MR imaging of physiologic hypertrophy in adolescence. Radiology. 1990 Mar;174(3 Pt 1):681-5. doi: 10.1148/radiology.174.3.2305049.

12. Simpkins JW, Estes KS. Role of monoaminergic neurons in the age-related alterations in anterior pituitary secretion. In: Nemeroff CB, Duun AJ, editors. Peptides, Hormones and Behaviors. New York: Spectrum Press; 1984:823-863.

13. Daghighi MH, Seifar F, Parviz A, Poureisa M, Hajibonabi F, Daghighi S, et al. The Effect of Females' Reproductive Factors on Pituitary Gland Size in Women at Reproductive Age. Medicina (Kaunas). 2019 Jul 11;55(7):367. doi: 10.3390/medicina55070367. 